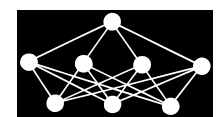

\title{
PARAMETRIC SENSITIVITY IN DECISION MAKING PROCESS
}

\author{
P. Moos, M. Novák, Z. Votruba*
}

\begin{abstract}
This paper introduces a possibility of application of parametric sensitivity appearing in processes of decision making in systems represented by the general production functions of the Tinbergen type, depending on information content, information flow and qualification of human resources. The so-called parametric sensitivity considering the information content $I$ as an ordering parameter, dependent on the information flow $\phi$, applied on production function. The theory of production function describes the relation between physical outputs of a production process and physical inputs, i.e. factors of production. Finally, the influence of knowledge in information content $I$, leading to correct decision, is demonstrated through the parametric sensitivity concept. For this invention, J. Tinbergen and R. Frisch achieved in 1969 the "Nobel price of the Swedish National Bank". Besides, the production functions theory surprisingly represents also a tool for finding the reasons of living bodies behavior.
\end{abstract}

Key words: production function, information, knowledge, Tinbergen, sensitivity, decision making, managing systems, business processes

Received: January 22, 2019

DOI: $10.14311 / \mathrm{NNW} .2020 .30 .003$

Revised and accepted: February 19, 2020

\section{Introduction}

The fact that the general production function proposed by J. Tinbergen [1-3], depends on information flow, information content and the basic knowledge incorporated trough the qualification of human resources is generally known ${ }^{1}$. In economy is obvious, that this role is on funds of labor $P$ and funds of capital or resources $F$. The quality of management of production processes gives mainly the quality of decision making, where the information content $I$ plays a dominant role.

*Petr Moos - Corresponding author; Mirko Novák; Zdeněk Votruba; Czech Technical University in Prague, Faculty of Transportation Sciences, Prague 1, Konviktská 20, Czech Republic, E-mail: moospetr@fd.cvut.cz

${ }^{1}$ In 1969 Dutch economist Jan Tinbergen and Norwegian economist, Ragnar Frisch shared the first "Nobel Prize" in economics "for having developed and applied dynamic models for the analysis of economic processes." It can be interesting to mention as well that Nikolaas Tinbergen, younger brother of Jan Timbergen, Dutch biologist shared the 1973 Nobel prize in physiology or medicine with Karl von Frisch and Konrad Lorenz for their discoveries of individual and social behavior patterns in animals and living systems. The works of both Tinbergens are nevertheless fruitful for the Systems Theory as a whole. 
The probability of correct decision is sensitive on the information content $I$, which further depends on received information flow $-\varphi$ and the knowledge $\mathrm{k}$. The knowledge is the main factor determining the potential of the system to make interpretation of the information content $-I$ from the information flow $\varphi$. For good decision-making process the attempt to the basis of knowledge $-k$ is important. Then, the sensitivity of data content on data flow with a knowledge $k$ as a parameter we call - the (parametric) sensitivity.

The use of the production function in praxis performs the evaluation of the physical outputs and inputs based on their prices. The economic value of physical outputs minus the economic value of physical inputs is the income that is achieved in the production process. Compliance with fixed prices between the two reporting periods leads to a change in income that is achieved via a change in the production function. The production function turns to be a practical concept, i.e. measurable and understandable in practical situations. For example, higher energy prices and growing concerns about global change lead to a number of policy objectives and targets aimed at curbing global warming and / or developing alternative sources of energy.

The inputs to the production function are commonly termed - factors of production, and among them, it is necessary to recognize information and the relevant knowledge.

According J. Tinbergen's Nobel Price lecture: The use models - experience and prospects, (Lecture to the memory of Alfred Nobel, December 12, 1969): "The primary factors of production were land, labor and capital (or raw materials). Primary factors do not become part of the output product, nor are the primary factors, themselves, transformed in the production process. The production function, as a theoretical construct, may be abstracting away from the secondary factors, and intermediate products consumed in a production process. The production function is not a full model of the production process: it deliberately abstracts from inherent aspects of physical production processes that some would argue are essential, including error, entropy or waste, and the consumption of energy, or the co-production of pollution".

A precise knowledge of mutual relations is possible by the technique of quantitative models only. The lack of homogeneity of raw information is the main cause of the lack of success in the social field, which is why the refinement of the basic material is necessary. The effort to take into account a large number of factors leads to increasingly complicated models and therefore threatens model management. This highlights the need for several stages of decision-making, and therefore planning. Highly significant is also the organizational aspect of decision-making, a correspondence between the organizational configuration of an optimal socioeconomic order and the levels and stages of planning. Consequently, the use of specific models for this purpose is desirable. One of the future characteristics of such a configuration will also be the more precise localization of information flows and, more particularly, of the type of information content required. Just two dimensions are often taken into account in the practical elaboration; but there are indications, that many more dimensions used in practice, correlates to some extent as well. Some earlier authors have worked with one dimension only; sometimes the IQ were used, and another proposal [3] concerns the degree of leadership as 
the one variable describing a man's ability to make decisions in production. These attempts are obviously oversimplifications, but with two basic factors $(P$ - labor, $F$ - funds) one could probably attain a satisfactory first approximation approach. A simplified interpretation of the application of the theory of production functions is successfully captured on examples in the English Wikipedia [14] and, of course in original works $[1,2]$.

In spite of the criticism of weak theoretical backgrounds, it has been recognized that empirical results firmly support the use of in principle simple production functions.

\section{It is not just about computing}

People from the computer branch of society in particular, tend to view the world from the technology outwards, while most general managers view all technology as separate and secondary to their business function and function as a support of the creative thinking.

This has also high importance in many technical areas, especially in the development or innovation in transportation technologies. This approach to engineer's activities in business organizations leads to poor communication among management and the understanding the value of other people contributions to the essential team work.

Modern managers in the business should understand how to use new tools as information and knowledge basis at their disposal, and, in particular, the tools for handling information - the most fundamental of all basic resources. Thus, the issues are much more complex than simple consideration of cost reduction through automation. It is not simply about replacing human effort by automation. It is not simply about replacing human effort by machines, not only about handling very high value complex transactions, not about storing large volumes of data, although all these factors will take place within an information network. it is not only about automating project of business processes, but it is about communicating, that is, transferring information and knowledge between people and between project and business processes. On that attributes of informatics is based the effectiveness of new integrated production and technologies.

Information management, using information technology as the tool, is all about the efficient running of the projects and in final form, in business. Today, this means that all forms of electronic, optical or optoelectronic storage, retrieval, processing, transmission and presentation of information is in cost - effective way to support project design and business needs in the transformations process within a production policy. However, not only the information flow, the knowledge basis, knowledge sharing systems and knowledge management systems (KMS) determine the quality of decisions in production processes.

Tinbergen rule states that for any policy goal, there have to be at least one policy tool. If fewer tools than targets are to disposal, then some policy goals could not be achieved. Further complication of the public policy environment are the facts that some policy tools affect more than one target, and others, while meeting one target, make addressing other targets more difficult. Some targets are also more efficient, than the others are. 
If the policy makers are going to be able effective meet their environmental and energy goals, a series of policy tools need to be developed

\section{All organizations are the information systems}

Information is the primary resource necessary for human. The information content is measurable as the parameter decreasing the uncertainty in decision processes. Ultimately, this resource influences all other factors. Even the supply of food, man's most important physical resource, depends on the accumulation of data.

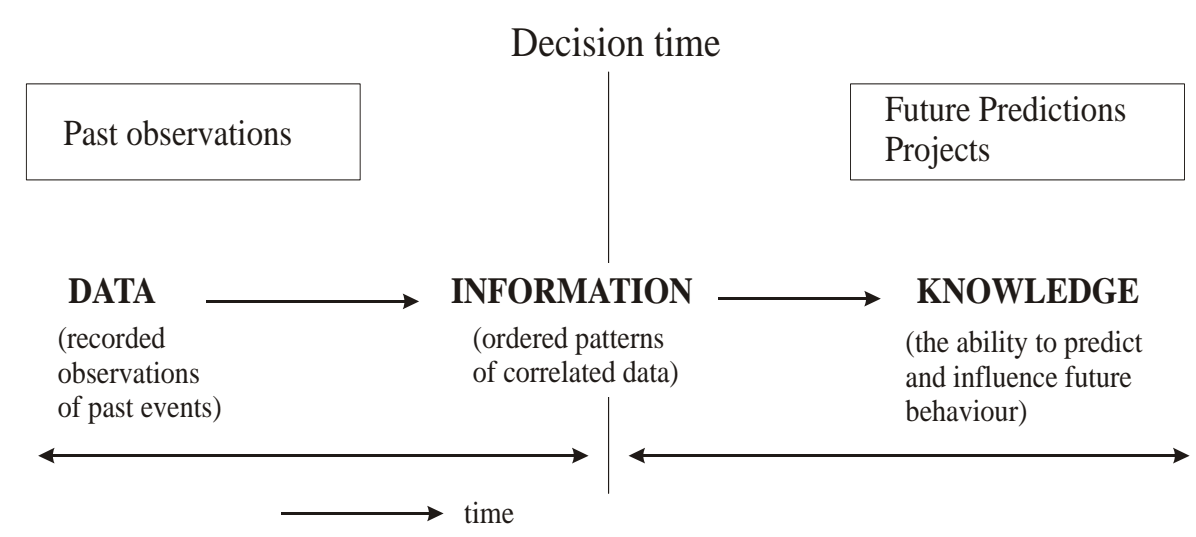

Fig. 1 Relations between data, information, knowledge and time.

These data are then ordered in patterns of linked and correlated facts that are termed "information" (see Fig. 1), where the sketch of information chain is shown.

This is then used by the human mind to create some new knowledge, which brings not only ability to predict, plan and execute change, but it is the carrier of new technologies the process of transfer.

Both the data and information relate to observation of behavior in past.

Isolated, not interpreted data are not suitable for the use in decision-making process. The information via its information content is giving the answer to questions: who, where, when, etc. Knowledge is obviously answering the questions: why and how. This is the root of the description of the knowledge.

Today, the knowledge base and the so-called inferences machines are the important parts of the artificial intelligence, which plays now the dominant role in many fields of engineering practice.

All human organizations, starting from the family unit, exist primarily because their members agree a common purpose and share the information that allows them to accumulate physical resources.

All human organizations are therefore characterized by the way, in which they share information representing the flow of energy, materials, labor, finances and flow of data.

All organizations are therefore some kinds of the information systems $[6,7]$. 


\section{Information - the key to competitive survival}

While almost each organization commonly manage physical resources of labor, materials, property and money, it usually manage a systematic way to the primary resources, i.e. the information.

In addition, such an excellent person, as e.g. N. Tinbergen was not enough oriented on information resources, probably because in his times, he had almost none, or quite low possibility to deal with automatic artificial information tools as knowledge basis and knowledge sharing systems.

The information resource management or KMS is now about managing the corporate information and knowledge, than it provides in a similar systematic way to the physical resources of the company.

In Fig. 2 is a representation of the various domains in which a typical manager now has to operate.

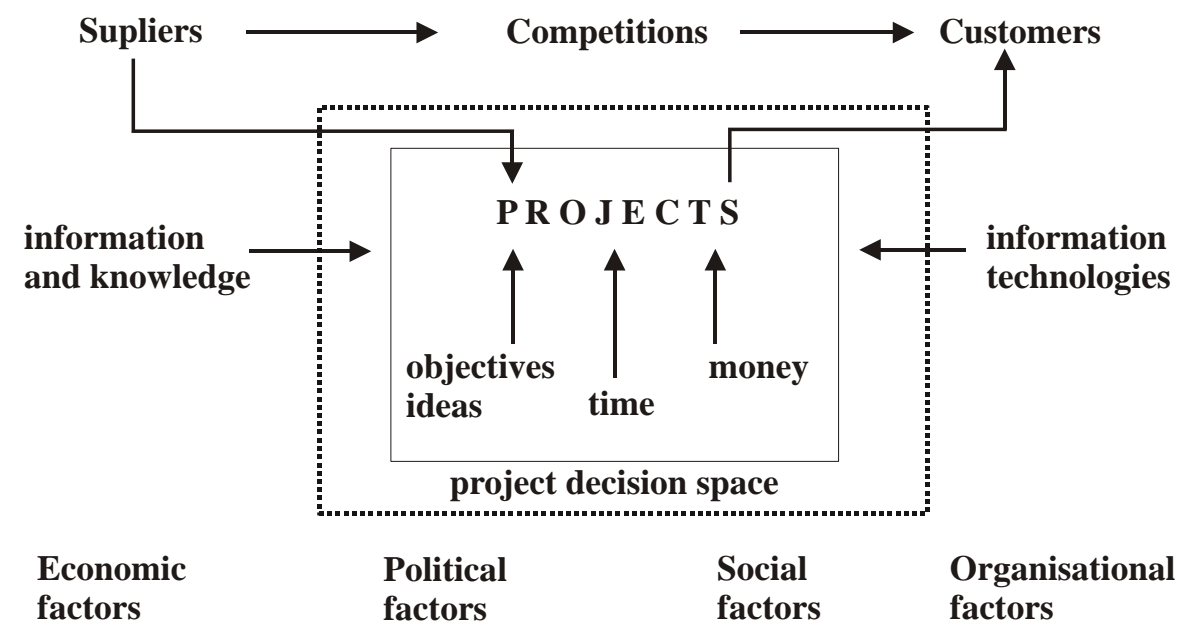

Fig. 2 Operation domains of contemporary manager.

To express the meaning of the information more accurately, the mathematical tools of the economic macro-modelling also in information area are to be carried out, especially in the production functions area (see $[1-4,8,9]$ e.g.)

The Tinbergen's dynamic production functions has the form:

$$
y(t)=a_{0} e^{\gamma t} F_{\tau}^{\alpha \tau} P_{t}^{\beta t},
$$

where

$a_{0} \mathrm{e}^{\gamma t}$ represents the influence of organization, which further reflects the

influence of information, either gained or self-generated,

$F_{t}$ is a time dependent value of basic resources (the so-called funds),

$\alpha=\partial y / \partial F \cdot F / y$ is the coefficient of relative sensitivity on founds,

$P_{t}$ is the value of labor,

$\beta=\partial y / \partial P \cdot P / y$ is the coefficient of relative sensitivity on labor,

$y(\mathrm{t})$ is a function of the resulting product of the modelled systems on time. 


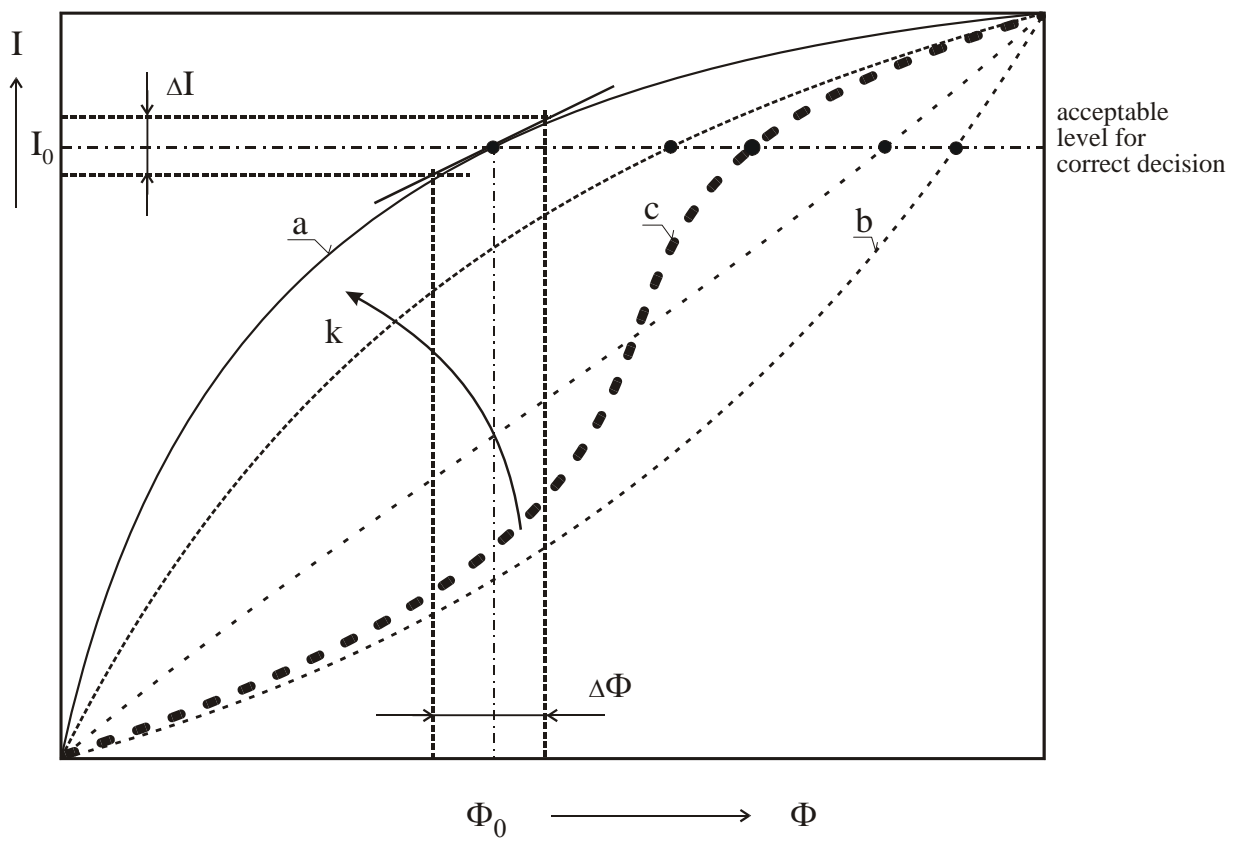

Fig. 3 The dependences between previous parameters $\Phi$ and I.

As one can expect, all the parameters introduced above are depending on the system structures.

To create good organization it means to reach such a graph representation of the system, which is able to maximize the production function.

To minimize risks given by the variations of parameters in the parts of the system, one needs to minimize the so called parametric sensitivity in decision making process influencing the production function $y(\mathrm{t})$.

\section{Parametric sensitivity}

The instant value of the production function in reality depends namely on information flow $\Phi$ and on the information content $I$ (if primary parameters $P$ and $F$ are constant):

$$
y=f(\Phi, I, K)
$$

where

$\Phi$ is the information flow,

$I$ is the information content,

$K$ is the knowledge.

The significant role has the information parametric sensitivity $S_{P}$ approximated by the gradient of linearized function as well as the sensitivities $\alpha$ and $\beta$ :

$$
I=h(\Phi, k) .
$$


Parameter $k$ represents either the natural or the artificial knowledge $\mathrm{K}$, installed in the system.

The gradient

$$
S_{\Phi_{0}}=\frac{\partial I}{\partial \Phi} \| \Phi_{0}
$$

is to be evaluated in the operating point $\Phi=\Phi_{0}$ that determines the know-how, being necessary to reach the level $I_{0}$, i.e. acceptable for correct decision level (see Fig. 3).

With respect to the parameter $k$, which variates with the system ability to learn, it results from data flow $\Phi$ and from the increase of the information content $I$ of the information difference:

$$
\mathrm{d} I=S_{k}^{I} \cdot S_{\Phi}^{k} \cdot\left(\Phi-\Phi_{0}\right),
$$

where $S_{\Phi}^{k}$ is the internal sensitivity, representing the approximation of learning ability of the information system.

The instant value of the information content is then approximately expressed as

$$
I(\Phi)=h\left(\Phi_{0}, k_{0}\right)+S_{k}^{I} \cdot S_{\Phi}^{k} \cdot\left(\Phi-\Phi_{0}\right) .
$$

The learning ability allows increasing the level of information content that is necessary for correctly made decision. The sensitivity

$$
S_{k}^{I}=\frac{\partial I}{\partial t}, \text { for } \Phi-\Phi_{0}
$$

and the sensitivity

$$
S_{\Phi}^{k}=\frac{\partial k}{\partial \Phi}, \text { near } \Phi-\Phi_{0}
$$

are both the so-called internal sensitives.

The sensitivity $S_{\Phi}^{k}$ one calls also the parameter of learning ability - PLA.

\section{Conclusion}

The decision making process on the government level mainly needs the risk assessment concerning probability of correct decision. If the economic decisions are testified by contribution to production functions, than the sensitivities on partial factors are needed, see for example [11] and [12].

The meaning and limitation of the Tinbergen production functions model is demonstrated for example in [13]. It is clear, that information flow and information content have outstanding role in economy. Often is proclaimed, that for economic growth one needs the information power.

If one accepts the hypothesis that information power correlates to production function, then it corresponds to the relation:

$$
P_{I}=I_{0} \cdot \Phi_{0} .
$$

The parametric sensitivity, which is based on the learning ability of the system increases the information power by the difference

$$
\mathrm{d} P_{I}=\Phi_{0} \cdot\left[S_{k}^{I} \cdot S_{\Phi}^{k}\left(\Phi-\Phi_{0}\right)\right]
$$


which further increases the probability of final quality in decision-making process.

According De En Moon [10], the estimation of the effectiveness of alternative options exists when choosing the direction of development of, for example, the national economy is difficult problem. To solve this problem, the author [10], worked out a new tool in the form of a modified production function $(\mathrm{PF})$ with variable parameters, based on the hypothesis of the variability of the rate of economic growth due to technical progress. Variability to the technical growth is given mostly by using new know-how, it means by new knowledge $k$. This effect demonstrates the internal structural sensitivity of the production function PF. Using the modified $\mathrm{PF}$ reduces to a common base year the source data and estimate the PF for nonhomogeneity periods, which have both the periods of growth and decline.

In the presented analyses, the interest not only express the average annual contribution of production factors to product growth, but by the direct contribution of variable factors to product growth. The same result can be achieved both due to the extensive growth of production factors, and due to their qualitative growth.

\section{Related works}

If the reader is interested in obtaining information on the subject from a broader context, we recommend publications as follows:

- Sensitivity Analysis, https://en.wikipedia.org/wiki/Sensitivity_analysis.

- BORGONOVO E., PECCATI L. Sensitivity Analysis in Decision Making: A Consistent Approach. Advances in decision making under risk and uncertainty. Selected papers based on the presentations at the 12th international conference on the foundations and applications of utility, risk and decision theory (FUR XII 2006), Rome, Italy, June 22-26, 2006, pp. 65-89.

- RAPPAPORT A. Sensitivity Analysis in Decision Making. The Accounting Review. 1967, 42(3), pp. 441-456.

\section{References}

[1] TINBERGEN J. Business Cycles in the United States, 1919-1932. Geneva: League of Nations, 1939, doi: 10.2307/1232097.

[2] TINBERGEN J. Business Cycles in the United Kingdom, 1870-1914. Amsterdam: NorthHolland, 1951.

[3] TINBERGEN J. On the Theory of Economic Policy. Amsterdam: North-Holland, 1952.

[4] HUŠEK R., MAŇAS M. Mathematical models in economy (in Czech: Matematické modely v ekonomii), SNTL, Prague, 1989.

[5] COOB CH., DOUGLAS P.H. A theory of production, Review of economic studies, 35, 1968, pp. 91-104, doi: 10.2307/2974410.

[6] MOOS P. Information technology (in Czech: Informační technologie), ČVUT, Prague, 1993

[7] VLČEK J., MOOS P. Methods of mathematical analysis and of design the structures with high reliability (in Czech: Metody matematické analýzy a návrh struktur s vysokou spolehlivostí). Technical Report, FD ČVUT, Prague, 1994.

[8] SEGAL A. An optimal control approach to dynamic routing in networks, IEEE Trans. Automat. Control, AC 17, 1982, pp. 329-339, doi: 10.1109/TAC.1982.1102915. 
Moos P., Novák M., Votruba Z.: Parametric sensitivity in decision...

[9] MOOS P. The role of structural sensitivities, Neural Network World, 1995, 6, pp. 917-928.

[10] De En MOON: Estimation of the Contribution of Intensive Factors of Economic Growth of the USA. Proceedings of the International Scientific Conference "Far East Con" (ISCFEC 2018).

[11] HAJKOVÁ D,. HURNíK J. Cobb-Douglas Production Function: The Case of a Converging Economy, Czech Journal of Economics and Finance, 2007, 9-10, pp. 465-476.

[12] LINDENBERGER D. Service Production Functions, EWI Working Paper No. 03.02, Institute of Energy Economics, University of Cologne (EWI), Cologne, 2003.

[13] HECKMAN J.J. The Race between Demand and Supply: Tinbergen's Pioneering Studies of Earnings Inequality. DISCUSSION PAPER SERIES, IZA - Institute of Labor Economics, 12, 2018, doi: 10.3386/w25415.

[14] Wikipedia (English version)): Production functions https://en.wikipedia.org/wiki/ Production_20function [Accessed Nov. 2019]. 